\title{
EWSR1/ETV1 Fusion Protein
}

National Cancer Institute

\section{Source}

National Cancer Institute. EWSR1/ETV1 Fusion Protein. NCI Thesaurus. Code C99260.

A fusion protein encoded by the EWSR1/ETV1 fusion gene. This protein is comprised of the transactivation domain of the RNA-binding protein EWS followed by ETS DNA binding domain of the ETS translocation variant 1 protein. 